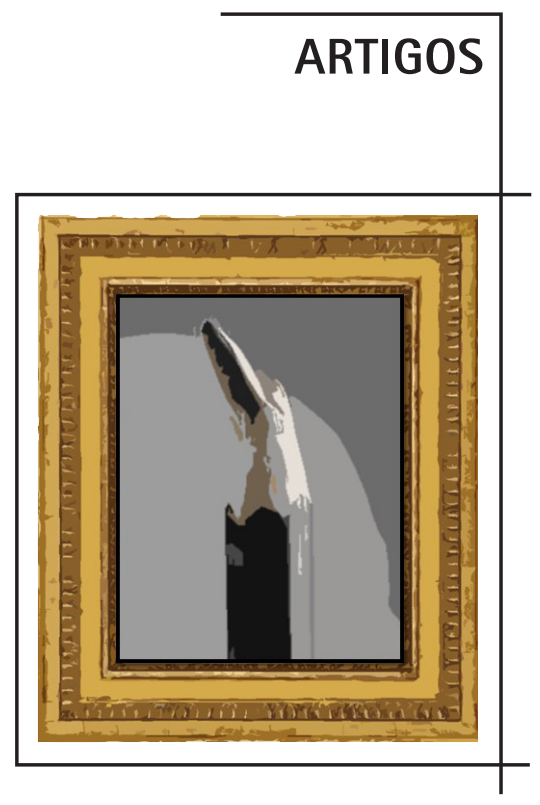




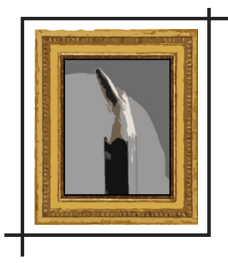

\title{
PEDAGOGIA SOCIAL: UMA ANÁLISE SOBRE A PRÁXIS DO EDUCADOR VOLUNTÁRIO DO CHILDREN'S INTERNATIONAL SUMMER VILLAGE
}

\author{
Rogério da Costa Ribeiro* \\ Suelly Aparecida Galli Soares**
}

Resumo: Em decorrência das demandas sociais por disseminação da cultura de educação para a paz, a atuação do educador voluntário tem ganhado campo de atuação no âmbito da educação escolar e não escolar. Este artigo aborda a práxis do educador voluntário da organização não governamental Children's International Summer Village (CISV), que se autocompreende como educação não escolar atuando em confluência com a educação escolar, sob o viés da educação para a paz. Uma perspectiva educacional que parte do pressuposto de que a paz se cria, num processo de construção contínua de justiça social, para um mundo mais justo, pacífico, solidário e humano. Essa abordagem visa investigar a atuação prática do educador voluntário do CISV e correlacionar os objetivos e princípios educacionais da organização CISV com os pressupostos da Pedagogia Social. 0 tema deste artigo interessa às áreas de Educação, Serviço Social e Gestão de Projetos. Trata-se de uma pesquisa qualitativa de cunho exploratório e descritivo. A observação participante do pesquisador na realidade em estudo foi utilizada como instrumento para coleta de dados. Como resultado, percebeu-se que a educação para a paz, tanto na perspectiva do CISV quanto da Pedagogia Social freiriana, parte do pressuposto que a paz se cria num processo de construção contínua.

Palavras-chave: Pedagogia Social. Educador voluntário. Educação não escolar. CISV. Educação para paz.

\section{INTRODUÇÃO}

À luz de um novo tempo que se descortinou no período do pós-guerra, inúmeras iniciativas sugiram no âmbito da sociedade em prol do ideal de um mundo de paz. Diversas organizações não governamentais (ONGs) foram criadas, em inúmeros países, para atender

\footnotetext{
* Mestre em Ciências da Educação pela Escola Superior de Educação Almeida Garrett (Lisboa/Portugal). Especialista em Gestão da Educação a distância pela Universidade Federal Fluminense (UFF). Pedagogo pela Faculdade de Pedagogia de Vargem Grande (FVGP).E-mail: ribeirorcr13@gmail.com

** Pós-Doutora e doutora em Educação pela Universidade Estadual de Campinas (Unicamp). Mestra em Educação pela Pontificia Universidade Católica de Campinas (PUC-Campinas).E-mail: suegallis@gmail.com
} 
a várias necessidades que assolaram a humanidade. Com o passar do tempo, algumas iniciativas foram sendo absorvidas pela área da educação, em virtude de determinadas necessidades de ordem sociais e não necessariamente pedagógicas. Nesse sentido, a educação para paz e a práxis do trabalho voluntário exercida pelo educador não escolar no âmbito da educação escolar constituem-se em tema de estudo que abre inúmeras possibilidades para o debate, explicitando pontos de convergência e/ou divergência educacional. Ambas se caracterizam como práticas da Educação Social.

A paz a que nos referimos não se restringe ao estado de bem-estar espiritual ou à ausência de conflito, a um dado ou fato intrínseco humano comum a todos, às nacionalidades e culturas. Ela precisa ser cultivada desde os primórdios da infância para que se possa falar em cultura da paz ou educação para a paz, em que não se escondem, mas desvelam-se com criticidade ética, as práticas sociais opressoras ou injustas.

A paz possibilitar-nos-á cultivar um mundo em que se incentiva a praticar a colaboração, a tolerância às diferenças, a justiça, a solidariedade e o convívio humano em comunidade. Nesse contexto, o trabalho voluntário também não se apresenta como uma realização pessoal, de ordem intimista ou espiritual, como oposto do trabalho remunerado ou da subserviência a um dado contexto social. Ele desponta como uma ação de intervenção no meio, tendo em vista uma transformação social, em prol de um mundo mais justo, participativo e pacífico.

Estas duas categorias, educação para a paz e trabalho voluntário, caracterizam-se como práticas de Educação Social. Ambos necessitam de coerência na práxis, expressando um modo específico de sentir, observar, pensar, respeitar a si e o outro, de dizer sua palavra.

Para essa reflexão, buscamos fundamentação em Paulo Freire, indicado para o Prêmio Nobel da Paz em 1993. Essa indicação nada mais é que uma valorização de sua postura coerente, impregnada pela generosidade, pela tolerância e pelo respeito às diferenças étnicas, religiosas e políticas. Um educador que atuou incessantemente em prol da paz por meio de sua práxis a serviço da autonomia e libertação do ser humano pela via educacional.

Ao ser contemplado com o "Prêmio Unesco da Educação para a Paz", reafirmou seu discurso proferido em Paris, em setembro de 1986:

De anônimas gentes, sofridas gentes, exploradas gentes aprendi sobretudo que a Paz é fundamental, indispensável, mas que a Paz implica lutar por ela. A Paz se cria, se constrói na e pela superação de realidades sociais perversas. A Paz se cria, se constrói na construção incessante da justiça social. Por isso, não creio em nenhum esforço chamado de educação para a Paz que, em lugar de desvelar o mundo das injustiças, o torna opaco e tenta miopizar as suas vítimas (FREIRE, 2006, p. 388).

Inspirados por esse entendimento sobre a paz, lançamos um olhar reflexivo a respeito da atuação do educador voluntário em sua práxis, como sujeito ensinante e aprendente da educação para a paz no contexto escolar de uma dada realidade social. 
Nessa perspectiva do sujeito que ensina e aprende num processo de mudança social, encontramos subsidio da Pedagogia Social freiriana em Moacir Gadotti (1996, p. 20) que, ao discorrer sobre as relações entre Educação Popular, Social e Comunitária, afirma:

Embora não tenha escrito especificamente sobre o tema, há um capítulo do livro Educação e Mudança sobre "0 papel do trabalhador social no processo de mudança" (FREIRE, 1979, p. 43-60) que nos remete ao debate atual em relação ao papel do "educador social". Ele se recusa a falar de um papel abstrato do trabalhador social em geral, já que, concretamente, ele tanto pode atuar pela "mudança social" quanto pela "permanência". A opção do trabaIhador social "irá determinar tanto o seu papel como seus métodos e suas técnicas de ação" (Id. ib., p. 49). Paulo Freire termina o capítulo afirmando que "tentar a conscientização dos indivíduos com quem se trabalha, enquanto com eles também se conscientiza, este e não outros nos parece ser o papel do trabalhador social que optou pela mudança" (Id., ib., p. 60).

Urge destacar que a vertente freiriana da Pedagogia Social se encontra em processo de construção no Brasil, com base nos pressupostos pedagógicos de Paulo Freire, e esse olhar tem contribuições a apresentar para a reflexão a que nos propomos realizar com este estudo.

Em consonância com os princípios freirianos anteriormente explicitados, tomamos como ponto de partida em nossa reflexão uma vivência prática inédita da ONG Children's International Summer Village (CISV) correlacionando os seus objetivos e princípios educacionais com os da Pedagogia Social.

À luz da busca pela configuração de uma sociedade que educa para a paz, por meio de vivências em comunidade, o educador voluntário do CISV atua como mediador de intercâmbio cultural e formador de sujeitos para o exercício da cidadania global participativa.

Trata-se de um aprendizado lúdico, que tem um papel educacional fundamental no desenvolvimento da pessoa, da comunidade local e da sociedade como um todo. Essa perspectiva está em consonância com os Parâmetros Curriculares Nacionais, no que diz respeito à necessidade de se construir uma escola voltada para a formação de cidadãos críticos, reflexivos, cientes da importância de seu papel na sociedade (BRASIL, 1998).

Nesse arcabouço da educação escolar e não escolar, temos a problematização da formação do sujeito, mais precisamente seu ponto de encontro ou desencontro no âmbito do educar para se aprender a aprender e a lidar como os conflitos emergentes na e da sociedade contemporânea, um desafio que se amplia no contexto do exercício da cidadania global.

0 objetivo deste estudo é investigar a atuação prática do educador voluntário do CISV e correlacionar os objetivos e princípios educacionais dessa organização com os pressupostos da Pedagogia Social.

Perguntamo-nos:

- Até que ponto a inserção do educador voluntário da educação não escolar na educação escolar encontra um campo profícuo? 
- Em que medida os objetivos e princípios educacionais da organização CIVS dialogam com os pressupostos da Pedagogia Social?

Movidos por essas indagações, mais do que buscar resposta dadas por este ou aquele autor, neste ou naquele seu texto, percebemos na Pedagogia Social freiriana uma possibilidade de diálogo e resposta para o nosso objeto de estudo numa perspectiva brasileira, tendo em vista o todo que constitui a obra de Paulo Freire. De acordo com Silva (2016, p. 15):

\begin{abstract}
Mais do que nos ater neste ou naquele texto de Paulo Freire para encontrar sua pedagogia social devemos enxergar a sua obra como um todo para entender as suas principais contribuições não só para a educação social, mas, certamente, para a educação popular e comunitária, tal como o fez Moacir Gadotti na obra Paulo Freire: uma biobliografia.
\end{abstract}

A vertente educacional freiriana se mostra atual em sua perspectiva pedagógica, e a Pedagogia Social brasileira, ao reinventar a perspectiva de Paulo Freire no prisma da Pedagogia Social, subsidia-nos para respondermos às questões que ora investigamos com o olhar esperançoso de ser possivel construir um mundo mais justo, pacífico, solidário e humano.

\title{
IDENTIDADE INSTITUCIONAL
}

A sigla CISV refere-se à ONG Children's International Summer Village, cuja denominação pode ser traduzida em português como "Comunidade de Férias Internacional para Crianças", mas, no Brasil é mais conhecida como "Convivência Internacional de Crianças e Jovens". A sigla CISV, com o passar do tempo, passou a ser considerada pelos integrantes do grupo como um "nome" de identidade (no gênero masculino). Essa instituição traz em seu propósito educacional o educar e inspirar ações para um mundo mais justo e pacífico, começando pela infância, sob o viés da educação para a paz.

0 CISV foi criado em 1951 pela Dra. Doris Twitchell Allen, no formato de uma ONG ligada à Organização das Nações Unidas para a Educação, a Ciência e a Cultura (Unesco), autocompreendendo-se como um organismo sem fins lucrativos, internacional, voluntário e apolítico. Propõe-se a oferecer diversas atividades como acampamentos nacionais e internacionais, intercâmbios familiares e projetos baseados em comunidades, denominados "programas", organizados anualmente por voluntários para um variado público de adolescentes, jovens e adultos em mais de 60 países.

Em 1949, final da Segunda Guerra Mundial, a Unesco propôs que estudantes de pós- graduação em diferentes disciplinas, nas universidades associadas, com ela se empenhassem para desenvolver organizações que versassem sobre a paz. Nesse período, Doris Allen, 
especialista em desenvolvimento infantil, apresentou à Unesco uma proposta de criação da organização educacional para atuar em longo prazo na educação para a paz.

A inciativa de Doris Allen traz em seu bojo, ainda que não nomeada, uma correlação com a teoria geral da educação social. Para Silva (2016, p. 13):

\begin{abstract}
A Teoria Geral da Educação Social que fundamenta as práticas de Educação Social, Educação Popular e Educação Comunitária é, por definição, inter e multidisciplinar, mas propõe uma visão de homem, de sociedade e de mundo na qual a natureza das relações e a qualidade destas devam ser essencialmente e predominantemente pedagógicas e se sobrepõe a qualquer dogmatismo ou doutrinação.
\end{abstract}

Urge destacar que, na perspectiva da Pedagogia Social, indivíduo e condições sociais da cultura e condições culturais da vida social se encontram interligados. Esse fundamento da Pedagogia Social foi cunhado por Paul Natorp (1913, p. 97 apud RIBAS MACHAD0, 2012, p. 12, grifo do autor), em seu livro Pedagogía Social: teoria de la educación de la voluntad:

\begin{abstract}
[...] a educação do individuo está condicionada socialmente às condições sociais da cultura e às condições culturais da vida social. 0 autor ainda complementa que uma verdadeira Pedagogia Social não pode esquivar-se da pergunta sobre as leis fundamentais da vida e da comunidade. Para ele, a palavra Pedagogia não significa somente a educação da criança nas suas formas tradicionais, mas sim se refere à obra inteira de elevação do homem ao alto da plena humanidade. A Pedagogia Social não é a educação do individuo isolado, mas sim do homem que vive em uma comunidade, porque a sua finalidade não é somente o indivíduo.
\end{abstract}

Com base nesses fundamentos da Pedagogia Social, o olhar sobre a obra de Doris Allen se amplia e adquire um significado profícuo. Percebemos, no marco histórico da proposta de Doris Allen, uma forte correlação com os fundamentos da Pedagoga Social.

Em 1951, Doris Allen montou o primeiro acampamento na cidade de Cincinnatti, nos Estados Unidos, com o objetivo de pôr em prática suas ideias sobre o que seria essa organização educacional. Essa iniciativa se deu com a participação dos filhos de seus amigos originários de oito paises diferentes, que residiam nessa cidade. Nesse acampamento, Doris Allen propôs que as crianças, por meio do convívio, vivessem a experiência de compartilhar suas semelhanças, diferenças de linguagem e tradição, buscando contribuir para o entendimento de como eram, pensavam, se comportavam, foram educados até o presente momento. Tratava-se do compartilhar as coisas de criança: formação de amizades, brincadeiras e modo de pensar.

0 primeiro acampamento recebeu o nome de Village e posteriormente passou a constituir-se em base para todos os demais "programas" da organização. 0 convívio entre seme- 
Ihanças e diferenças é capaz de promover ações e reflexões acerca da pessoa humana e das diferenças culturais. Trata-se de uma experiência vivencial capaz de promover contato social, conhecimentos, valores como amizade, afeto, respeito mútuo, compromisso consigo e com o outro, bem como a resolução de conflitos de modo pacífico.

A práxis cunhada com base em princípios educacionais, como o aprender a aprender e aprender fazendo e experimentando, encontra-se em harmonia com a perspectiva de Freire sobre o saber. Para Freire (2011, p. 81), o saber se constitui, impreterivelmente, em transformar: "só existe saber na invenção, na reinvenção, na busca inquieta, impaciente, permanente, que os homens fazem no mundo, com o mundo e com os outros".

Os programas proporcionam a oportunidade de conhecer e desenvolver amizades entre pessoas da comunidade local e de diversos países, promovendo experiências de vida e culturas. Todos os programas do CISV têm por foco a educação para a paz, com o intuito de inspirar participantes a se tornar cidadãos globais participativos.

O CISV se autocompreende como uma organização não governamental, originária da sociedade civil, unindo seus integrantes a partir de alguns princípios educacionais que refletem um modo de pensar e agir. Os seus princípios educacionais são:

Nós apreciamos as semelhanças entre as pessoas e valorizamos as suas diferenças. Nós apoiamos a justiça social e a igualdade de oportunidade para todos. Nós encorajamos a resolução de conflitos através de meios pacíficos. Nós apoiamos a criação de soluções sustentáveis para problemas relativos ao nosso impacto uns sobre os outros e sobre o meio ambiente (CISV INTERNATIONAL, 2009, p. 9).

Os educadores voluntários buscam em sua práxis fazer a conexão entre o propósito da organização e seus princípios educacionais com foco na educação para a paz. Com esse olhar educativo, objetivam promover a inclusão, justiça social, resolução pacífica de conflitos e o desenvolvimento sustentável, auxiliando cada participante a desenvolver a compreensão de que cada sujeito pode agir em favor de um mundo mais justo e pacífico. A instituição se propõe também a contribuir para a pesquisa científica e atuar em parceria com outras organizações que possuem objetivos educacionais similares, sem preferência de etnia, nacionalidade, cultura ou condição econômica.

Os princípios educacionais que subsidiam a educação para a paz e o trabalho voluntário no CISV possuem fundamentos educacionais próprios, similares aos da Pedagogia Social freiriana. Vale lembrar, segundo Silva (2016, p. 10):

Embora o próprio Paulo Freire - reconhecemos - não tenha usado o termo Pedagogia Social, toda sua obra é orientada para um único propósito: desenvolver no ser humano a vocação de ser mais, tendo como pressupostos teóricos e práticos para a transformação 
social, a liberdade, a autonomia, a emancipação, a consciência de si, do outro e do seu lugar no mundo.

Para formar cidadãos globais participativos, o CISV trabalha com o desenvolvimento de atitudes, habilidades e conhecimentos (attitudes, skills and knowledge - ASK). Esse olhar educativo constitui o núcleo das ações pedagógicas da atuação do educador voluntário em sua abordagem e suas vivências dos objetivos educacionais.

O CISV compreende por atitude a forma como os sujeitos pensam e se comportam, vislumbrando que se tornem cada vez mais abertos a novos hábitos e opiniões, tornem-se flexíveis, desenvolvam a vontade de incluir pessoas, assumam a responsabilidade por suas ações e decisões. Compreende por habilidade a capacidade de comunicação, liderança, autoconhecimento e resolução criativa de problemas. Compreende por conhecimentos a aquisição de informações por meio de aprendizado em grupo e de experiência vivencial com comunidade em diferentes dinâmicas populacionais, problemas comunitários, questões ambientais, fatos geográficos e históricos.

0 processo de formação do cidadão global participativo desenvolvido pelo CISV pode ser entendido como congruente com a Pedagogia do oprimido de Paulo Freire (2011, p. 43), em "que tem de ser forjada com ele e não para ele, enquanto homens ou povos, na luta incessante de recuperação de sua humanidade". O CISV, por meio de seus programas, possui quatro objetivos educacionais centrais, compostos por ASK, pautados na descrição feita anteriormente.

Assim, os seus objetivos educacionais se articulam em torno de quatro grandes áreas: diversidade, direitos humanos, conflitos e resoluções, desenvolvimento sustentável. Quando se abordam essas quatro áreas na práxis do educador voluntário, almeja-se sucessivamente, não de forma linear, mas em espiral:

- Explorar a identidade do indivíduo e levá-lo a questionar a sua postura tanto dentro das próprias comunidades quanto na comunidade global.

- Considerar como os direitos humanos afetam cada aspecto de sua vida e como as violações desses direitos se encontram na raiz de problemas como a pobreza, a violência e a ilegalidade.

- Entender como os conflitos podem agir deliberadamente ou de outra forma, e o que pode ser feito para alcançar uma resolução pacífica.

- Buscar métodos integrados para promover o bem-estar social e econômico, enquanto protege o meio ambiente por meio do uso responsável dos recursos naturais.

Dessa forma, a educação para a paz na metodologia do CISV, por meio de dinâmicas de grupo e convivência em comunidade, pode se relacionar a uma dessas quatro áreas ou à 
combinação de duas, três ou todas as quatro. Esse horizonte educacional se constitui em norte referencial para o educador voluntário no planejamento das ações, garantindo que as questões abordadas se tornem interessantes e relevantes para o grupo envolvido nas atividades práticas. Essa abordagem e esse olhar educativo pretendem que os participantes se apropriem da educação para a paz no contexto de um dos programas que desenvolve suas atitudes, habilidades e conhecimentos, constituindo-se em cidadão global participativo.

As áreas e os objetivos delineados pelo CISV são similares ou têm similaridade com os princípios e pressupostos da Pedagogia Social. À medida que o educador voluntário do CISV atua em prol da transformação de um dado contexto, tendo em vista a educação para a paz, com a promoção de um mundo mais justo e pacífico, a sua práxis se alinha com a práxis do educador social, o qual possui essa vertente como norteador do seu agir.

No CISV, entende-se que a educação para a paz se constitui em um processo que necessita de tempo e amadurecimento para consolidar-se. Por isso, propõe diversos programas voltados a diferentes faixas etárias e uma continuidade cíclica valendo-se de temas.

Utiliza "temas" para oferecer uma experiência única em cada programa, que são desenvolvidos a partir das quatro áreas já descritas. Os temas são utilizados para conectar o conteúdo educacional diretamente aos objetivos de cada programa. No planejamento do tema e na execução de cada programa, devem-se considerar diversos fatores, inclusive:

0 local e as suas caracteristicas; Idade dos participantes; Duração do programa; Campanhas nacionais e internacionais; Questões e problemas locais; Eventos mundiais; Tamanho do grupo; Organizações parceiras; Disponibilidade de recursos; Custos; Dinâmicas de grupo; Relevância para o grupo; Complexidade da questão (CISV INTERNATIONAL, 2009, p. 20-21).

Apoiada nesse foco vivencial, por meio da experiência em comunidade, investe na lembrança que os participantes terão sobre as amizades constituídas, a diversão que experimentaram juntos e as atividades que realizaram.

As atividades práticas são escolhidas pelo educador voluntário, durante o planejamento em equipe, para apoiar o "tema" e oferecer aos participantes a oportunidade de aprender mais sobre eles mesmos e em como desenvolver suas ASK para que possam se tornar cidadãos globais participativos. A organização possui um banco de dados de atividades em inglês, disponivel na rede (http://resources.cisv.org), que subsidia os educadores voluntários.

Parte-se do pressuposto de que se aprende fazendo e acredita-se que esse aprendizado pela experiência é eficiente e divertido. Esse princípio constitui-se no cerne da prática do educador voluntário do CISV, pensado num processo de quatro passos:

1 Fazer: uma atividade de Educação para a Paz; 3 Refletir: sobre quais ASK você aprendeu nesta atividade; 3 Generalizar: como este novo aprendizado pode ser aplicado em diferentes contextos; 4 Aplicar: suas ASK em ações concretas (CISV INTERNATIONAL, 2009, p. 22). 
Com base nesse ciclo experiencial, acredita-se que algumas vezes a parte "aplicar" do processo terá lugar dentro de um programa CISV. Entretanto, sabe-se que o processo leva tempo e que a oportunidade certa para aplicá-lo pode só surgir depois do programa. Assim, o aprendizado pela experiência ajuda os participantes a se tornar cidadãos globais participativos. Esse modo educacional de pensar e agir se pauta no aprendizado pela experiência e faz ecoar uma fala de Confúcio (551 a. C.): "Eu escuto e esqueço, eu vejo e lembro, eu faço e compreendo" (CISV INTERNATIONAL, 2009, p.24).

Em síntese, a concepção antropológica que dá sustentabilidade à práxis do educador, tanto na perspectiva do CISV quanto da Pedagogia Social freiriana, é que o ser humano possui um forte potencial para ser mais como sujeito, embora sempre inconcluso.

\section{VIVÊNCIA NA ESCOLA PÚBLICA: UM RELATO DE ATUAÇÃO PRÁTICA DO EDUCADOR VOLUNTÁRIO}

0 CISV atua há 65 anos no Brasil, e, até o presente momento, as suas vivências no âmbito do núcleo regional do estado de São Paulo se estenderam à educação privada.

Em 2016, líderes voluntários da organização procuraram a Secretaria de Educação de Cotia e apresentaram sua intenção de realizar uma iniciativa com o setor público no intuito de expandir as suas atividades de educação para a paz. Tratava-se de uma iniciativa-piloto inédita na trajetória do CISV no Brasil, pelo núcleo institucional de São Paulo.

0 primeiro contato dos representantes voluntários CISV com a unidade escolar foi mediado pela Secretaria de Educação, via reunião de lideranças (membros do Departamento Pedagógico, CISV e direção escolar). Esse encontro propiciou uma primeira socialização da proposta de trabalho do CISV com a Escola Municipal Samuel da Silva Filho, onde se apresentaram sua forma de atuação, seus princípios e objetivos educacionais em que se pautam os representantes voluntários (aspectos já explicitados). 0 diálogo culminou no consenso sobre algumas ações a serem efetivadas e num cronograma inicial de trabalho conjunto.

Primeiramente, estabeleceu-se a efetivação de um encontro formativo com os professores de Educação Física da unidade escolar em que se realizaria a vivência-piloto com os alunos e demais professores de Educação Física do Ensino Fundamental II das outras escolas. Essa definição inicial se deu a partir do entendimento consensual de que esse componente curricular do Ensino Fundamental II é o que mais se aproxima da proposta da instituição, por causa de sua metodologia lúdica e coletiva de trabalho.

Posteriormente, efetivou-se uma vivência na Escola Municipal Samuel da Silva Filho, em dois momentos: um diálogo com todos os professores e uma vivência rápida de algumas dinâmicas de grupo; uma vivência prática, em forma de oficinas em grupos de convivência com os alunos dos sextos anos. Todas essas ações contaram com a participação de integrantes do Departamento Pedagógico e Departamento de Supervisão da Secretaria de Educação. 
Esse percurso e esses diálogos entre lideranças educacionais (voluntário CISV, Secretaria de Educação e direção escolar) explicitam, ainda que embrionariamente, um potencial de transformação na atuação educacional. Na perspectiva de Paulo Freire (2011), a práxis é transformação, bem como conquista de pessoas que atuam em colaboração para a efetiva análise crítica sobre a realidade e a formação do sujeito.

\section{ENCONTRO FORMATIVO COM OS PROFESSORES}

0 encontro formativo com os professores de Educação Fisica, realizado na Secretaria de Educação em 12 de maio de 2016, contou com a participação de professores de cinco escolas de Ensino Fundamental II da Rede Municipal de Ensino e representantes do Departamento Pedagógico e Departamento de Supervisão de Ensino da Secretaria de Educação. Já o encontro com os professores na Escola Municipal Samuel da Silva Filho, em 21 de maio de 2016, foi realizado com o corpo docente das demais disciplinas e a equipe gestora da unidade escolar, bem como com representantes do Departamento Pedagógico e Departamento de Supervisão da Secretaria de Educação.

Os dois encontros foram delineados com base no pressuposto de que se aprende fazendo, e, segundo a filosofia lúdica CISV, esse aprendizado pela experiência é eficiente e divertido. 0 encontro realizado na unidade escolar com os professores se deu brevemente no período da manhã, porque as oficinas a seriam realizadas no período da tarde com a participação dos alunos. Apresentaram-se uma sintese da metodologia educacional CISV e o roteiro a ser efetivado no período da tarde. Mantendo o elemento surpresa dos detalhes das atividades, a equipe foi orientada sobre seu papel de mediação nos grupos de trabalho com os alunos, em parceria com os voluntários CISV.

O diálogo com os professores se deu com base nos quatro passos da metodologia CISV: o fazer (vivência de uma atividade de educação para a paz, ou seja, dinâmica de grupo); o refletir (sobre quais ASK foram aprendidas com essa atividade); o generalizar (como esse novo aprendizado pode ser aplicado em diferentes contextos); o aplicar (os ASK em ações concretas). Foi uma exposição oral, como roda de conversa, aberta para esclarecimento de dúvidas e perguntas.

Com base nessa metodologia de trabalho formativo adotado pelo CISV, podemos nos remeter à diferenciação que Paulo Freire faz entre o animal e os homens, ou seja, somente os homens são seres de práxis. E "práxis que, sendo reflexão e ação verdadeiramente transformadora da realidade, é fonte de conhecimento reflexivo e criativo" (FREIRE, 2011, p. 127). Esse olhar freiriano sobre a práxis dialoga com a ação e reflexão propostas pelo CISV, pois, para ambos, não se trata de etapas isoladas, estanques em partes. Elas se dão num ciclo dinâmico, em que há simultaneidade e dialeticidade em sua efetivação. Como disse Freire (2011, p. 73), "a reflexão, se realmente reflexão, conduz à prática". 


\section{VIVÊNCIA PRÁTICA COM OS ALUNOS DE SEXTO ANO}

Toda vivência prática da organização CISV, por meio de seus programas, visa oportunizar aos seus participantes (crianças, jovens e adultos) o contato com a diversidade (cultura regional, nacional ou internacional), bem como o autoconhecimento do próprio sujeito partícipe da convivência em grupo sobre si e a cultura na qual se busca experimentar o respeito às diferenças.

0 encontro ou a vivência prática desenvolvida com os alunos do sexto ano do Ensino Fundamental II da Escola Municipal Samuel da Silva Filho ocorreu em 21 de maio de 2016, num sábado letivo, com quatro horas de intensa atividade com os alunos. A escolha desse grupo de alunos se pautou no fato de essa faixa etária dos alunos corresponder à faixa etária de iniciação na metodologia CISV (10 e 12 anos).

A vivência foi uma adaptação, um recorte, com base no Programa Village, em que a idade dos participantes é entre 10 e 12 anos. 0 Programa Village do CISV tem a duração média de 28 dias de acampamento e, por meio de um roteiro ou itinerário de atividades, proporciona 0 autoconhecimento de onde os participantes vivem e como vivem, percebendo as semelhanças e diferenças deles. Em geral, desenvolvem-se atividades educacionais, esportivas e brincadeiras diversas, pautadas nos quatro passos do CISV (fazer/vivenciar, refletir, generalizar e aplicar).

A vivência realizada na Escola Municipal Samuel da Silva Filho foi coordenada pelos educadores voluntários do CISV de forma integrada com os professores, gestores da unidade escolar e os integrantes do Departamento Pedagógico e Departamento de Supervisão da Secretaria de Educação.

Inicialmente se fez uma organização em pequenos grupos (alunos e educadores), de acordo com o planejamento prévio realizado pela equipe organizadora. Em seguida, os grupos percorreram diversos espaços da unidade escolar realizando um circuito de atividades em grupo, sem roteiro predeterminado, somente orientado para participarem de todas as propostas disponibilizadas.

Propuseram-se jogos e brincadeiras (pega-pega corrente, telefone sem fio com desenho, nó humano, pirâmide humana, representação teatral, quebra-cabeça coletivo, roda de conversa e outros), como forma de lazer em que os alunos inicialmente experimentaram o brincar pelo brincar (fazer/vivenciar). A partir dessa vivência foram desafiados, em roda de conversa, no diálogo com os colegas e educadores, a pensar sobre o que realizaram (refletir sobre as ASK). Como o tempo estabelecido para a vivência no período era curto, as rodas de conversa foram pontuais.

Nas rodas de conversa, os participantes foram estimulados a explicitar suas sensações, percepções, atitudes e possiveis relações com o cotidiano do grupo e/ou da sociedade, um horizonte mais amplo (generalizar), correlacionado com a construção de um espaço de paz.

Os mediadores (educadores) se empenharam para que todos tivessem a oportunidade de se expressar. Atuaram como interlocutores nos diálogos para que todos os alunos pudessem 
interagir, bem como percebessem a importância desse ato de refletir sobre os valores e as atitudes explícitos ou implícitos à vivência. Também se buscou explicitar que a aplicação prática do que foi experimentado no convívio em grupo consiste em um processo (ações em curto, médio e longo prazos) que demanda vontade e perseverança em um projeto de vida (aplicar).

Quando os alunos não verbalizavam ou não manifestavam perceber a abrangência e as implicações no cotidiano de tais valores e atitudes, os mediadores intervinham com algumas indagações para que os alunos pudessem expressar-se a respeito. Em meio aos diálogos, os mediadores fizeram a ponte entre o que o grupo de alunos expunha e a educação para a convivência em grupo, de forma sutil, tendo como plano de fundo implícito o entendimento de "Paz como o viver e trabalhar em união, aprendendo a apreciar as similaridades e diferenças" (definição de paz incorporada pelo CISV).

No final das atividades, após os alunos se retirarem da unidade escolar, foi realizada uma roda de conversa entre a equipe CISV, educadores da unidade escolar e Secretaria de Educação. Fez-se uma breve avaliação do dia, em que se expuseram diferentes percepções da vivência realizada, o quanto foi significativo para cada um ou como um todo para a unidade escolar a realização das atividades.

Essa oficina ou vivência prática constituiu-se em uma breve amostra singular de diálogo entre educação escolar e não escolar numa ação efetivamente educativa, com aprendizado para os sujeitos envolvidos (alunos, professores e educadores voluntários). Sobre essa vivência, podemos dizer a partir da perspectiva da Pedagogia Social freiriana (FREIRE, 2011) que foi uma experimentação educacional em que o sujeito não se educa a si mesmo, mas os sujeitos se educam entre si por meio da mediação cultural.

Tendo em vista essa vivência, é importante destacar seguinte:

A Pedagogia Social e suas práticas - sejam elas Educação Social, popular ou comunitária pressupõe o entendimento de que Educação se faz ao longo de toda a vida, em todos os espaços e que todos nós somos potenciais educadores. Nenhum espaço seja público ou privado, e nenhum grupo social, qualquer que seja sua capacidade econômica ou nivel de escolaridade pode prescindir da Pedagogia Social, especialmente nestes tempos de intensas transformações nas relações em todas as instâncias e estruturas sociais (SILVA, 2016, p. 10).

Na perspectiva da Pedagogia Social, em consonância com a filosofia educacional do CISV, podemos pensar em uma educação que perpassa a vida toda, que se dá em diversos espaços e que há um potencial educacional em todos nós.

\section{CONSIDERAÇÕES FINAIS}

Participar dessa experiência, ainda que tenham sido breves os momentos e as reuniões, constituiu-se em uma vivência pessoal/profissional marcante, proporcionando o convívio e 
o aprendizado com o outro em prol da educação para a paz. Marcante no sentido de ter oportunizado uma percepção de que representações e modos próprios de agir, objetos de pesquisa social, são molas propulsoras de um trabalho educativo em prol de um mundo mais humanitário, solidário e pacífico.

Às vezes as pesquisas estão impregnadas do olhar do adulto sobre o que a criança sabe ou pensa, mas não exatamente o que elas têm a dizer de si mesmas e do mundo que as cerca. A dinâmica e abordagem CISV estimulam os educadores a ouvir a criança em seu exercício reflexivo sobre si e o mundo que a circunda. Uma perspectiva que torna fecundo o propósito de educar para a paz a partir da criança, considerando sua forma singular de ver e experimentar o convívio em grupo como forma de promoção de um mundo mais humanizado e solidário.

As atividades educativas seguem a lógica do olhar a partir do microcontexto em que o sujeito está inserido para abarcar o macrocontexto cultural, social, histórico e político. Uma metodologia que se constitui em "tecnologia social", na perspectiva da Pedagogia Social, ou seja, uma prática que pode ser replicada em outros contextos e um saber social capaz de resolver alguns problemas sociais. Há um movimento do micro para o macro, em que as crianças (em grupo de convivência) podem se conhecer, interagir, constituir ciclos de amizades, cooperar umas com as outras para alcançar um determinado objetivo comum e conhecer diferentes olhares e perspectivas, num exercicio de reflexão sobre como construir um mundo mais justo e humanitário.

Foram proporcionadas algumas vivências como ponto de partida, com a expectativa de que essa experiência se amplie para os lares de cada um, seus círculos de relações e assim por diante. Vale destacar a percepção de uma empolgação, uma adrenalina perante o novo, a diversão com o brincar e, no final do dia, uma mistura de euforia e exaustão. Essa exaustão, ora física e/ou ora psicológica, adveio dos embates em que afloraram sentimentos, das formas de ver e interpretar as relações pessoais ou interpessoais, da corporeidade latente e dos pequenos conflitos intencionalmente proporcionados pelas atividades. Toda essa complexidade de elementos é tomada como propulsores a serviço de uma educação para a paz.

Urge que se pense, na perspectiva da Pedagogia Social freiriana (FREIRE, 1996), em uma ação educativa que não se restrinja à reprise da educação já existente, mas que seja capaz de delinear uma base para a sociedade, um alicerce educativo que se valha das melhores alternativas de ensinamentos. Uma práxis capaz de inserir no meio social os individuos deixados às margens social e educacionalmente.

Em suma, a educação para a paz, tanto na perspectiva do CISV quanto da Pedagogia Social freiriana, parte do pressuposto de que a paz se cria num processo de construção contínua de justiça social. E justiça social que se efetiva por meio da generosidade, tolerância, amorosidade e valorização do humano latente em cada sujeito, ante as intermitentes relações sociais. Trata-se de elementos singulares que se concretizam na práxis, por meio do 
entendimento a respeito dos mecanismos fundamentais dos processos de aprendizagem, construção de conhecimentos, habilidades e concepções próprias.

\title{
Social Pedagogy: an analysis of the praxis of volunteer educators of Children's International Summer Village
}

\begin{abstract}
As a result of social demands for spreading the culture of education for peace, the role of the volunteer educator has gained playing field within the school and non-school education. This study addresses the practice of volunteer educator non-governmental organization Children's International Summer Village (CISV), which understands herself as non-school education working in confluence with school education, under the bias of education for peace. An educational perspective on the assumption that peace is created in a continuous process of building social justice, for a more just, peaceful, supportive and human world. This approach aims to investigate the practical application of voluntary educator CISV and correlate the objectives and educational principles of CISV organization with the assumptions of Social Pedagogy. The theme of this research interests in the areas of Education, Social Services, and Project Management. This is a qualitative study of exploratory and descriptive nature. Participant observation of the researcher actually study was used as a tool for data collection. As a result, it was realized that education for peace, both from the perspective of the CISV, the Social Pedagogy Freirean, assumes that peace is created in a continuous build process.
\end{abstract}

Keywords: Social Pedagogy. Educator volunteer. Education school not. CISV. Education for peace.

\section{REFERÊNCIAS}

BRASIL. Parâmetros Curriculares Nacionais. Brasilia: MEC, 1998.

CISV INTERNATIONAL. Passaporte CISV. Tradução, adaptação e impressão CISV Brasil. 2009. Disponivel em: <http://biblioteca.cisv.org.br/comunicacao/PassaporteCISVlow.pdf>. Acesso em: 5 abr. 2016.

FREIRE, A. M. Educação para a paz segundo Paulo Freire. Educação, v. 29, n. 2, p. 387-393, maio/ago. 2006.

FREIRE, P. Pedagogia da autonomia. Saberes necessários à prática educativa. 36. ed. Rio de Janeiro: Paz e Terra, 1996.

FREIRE, P. Pedagogia do oprimido. 50. ed. Prefácio Ernani Maria Fiori. Rio de Janeiro: Paz e Terra, 2011.

GADOTI, M. (Org.). Paulo Freire: uma biobibliografia. São Paulo, Cortez, 1996. 
RIBAS MACHADO, É. As relações entre a Pedagogia Social e a educação popular no Brasil. In: CONGRESSO INTERNACIONAL DE PEDAGOGIA SOCIAL, 4., 2012. Anais... Disponivel em: <http://www.proceedings.scielo.br/pdf/cips/n4v1/24.pdf>. Acesso em: 11 maio 2016.

SILVA, R. da. Os fundamentos freirianos da Pedagogia Social em construção no Brasil. Pedagogia Social: Revista Interuniversitária, n. 27, p. 179-198, 2016. Disponível em: <https://recyt. fecyt.es/index.php/PSRI/article/view/44162>. Acesso em: 10 abr. 2016. 